\title{
ENSINO DE FILOSOFIA, FILOSOFIA DE QUEM?
}

Dante Diniz Bessa

\section{Concepção institucional de filosofia e suas relações com a educação}

No âmbito da educação institucional a filosofia tem sido entendida como elemento de cultura com data de nascimento na história. É neste sentido que ela se tornou uma tradição: a tradição de pensar conceitualmente o mundo, pensá-lo na sua universalidade. Por ser uma tradição é que a filosofia permanece em nosso meio; passou de geração para geração e de cultura para cultura. É certo que nessas passagens sofreu transformações (desterritorializações e reterritorializações) que dizem respeito tanto ao filosofar como ao seu produto, as diferentes filosofias.

Segundo Deleuze (1991) ... "quando a filosofia se reterritorializa sobre o Estado de direito, o filósofo se torna professor de filosofia” ... (DELEUZE, 1991, p. 101). Isso porque, ainda segundo Deleuze, desde o século XVIII os filósofos perderam o plano de imanência de onde emergem os conceitos, restando para a história da filosofia as marcas de caracteres nacionais que constituem não mais que opiniões filosóficas ou filosofias de profissionais.

Desde aí se primou pela tentativa de dar à filosofia um estatuto científico e, com isso, transmiti-la como um saber suscetível de desenvolvimento, de progresso ou como algo já produzido, a ser reproduzido. A ciência passou a ser valorizada como hierarquicamente superior à filosofia. $\mathrm{O}$ pensamento filosófico passou a ser tarefa do pesquisador e professor de filosofia, como nos diz Giannotti:

Ao contrário de outras épocas, o filosofar de hoje é em geral trabalho remunerado. O filósofo é um funcionário, poucas vezes um escritor, vivendo de sua própria produção. Goza assim de um lazer ritmado pelo livro de ponto, pelos horários das aulas, onde se obriga a comunicar, com rígida periodicidade, o resultado de suas investigaçôes livres (...),[cujo] financiamento, ademais vem pelo Estado, pois são raras as fontes privadas onde possa obter recursos. $O$ filósofo 
de hoje é quase sempre um professor, às vezes aposentado (GIANNOTTI, 1985, p. 12).

O modo pelo qual a filosofia se institucionalizou, notemos, foi pela sua presença na educação escolarizada. Considerando, pois, essa educação filosófica, muitos professores e pesquisadores têm perguntado e proposto respostas sobre suas funções sociais e políticas. A resposta mais recorrente tem sido a de que a filosofia tem a função crítica de libertar das ideologias, dos dogmas, do tradicional, da ingenuidade, dos preconceitos. Mas nem por isso se deixa de pensar numa função para ela, num lugar institucional que ela possa ocupar.

As questões que passamos a investigar, a partir daqui, então, são as seguintes: 1) quem produz as filosofias que são ensinadas institucionalmente? 2) que efeitos essas filosofias podem ter no seu ensino?

Para ensaiar uma resposta, busquemos, primeiramente, subsídios históricos sobre o ensino de filosofia. Depois, vejamos como Nietzsche, um dos críticos mais veementes da vida moderna (institucional) olhou para isso, para, finalmente, pensar nas condições de possibilidade da educação institucionalizada da filosofia como criação.

\section{Condições históricas, filosóficas e pedagógicas do ensino de filosofia}

Como matéria de ensino, a filosofia tem sido ensinada desde os gregos antigos, ainda que não para todos os indivíduos. Platão e Aristóteles, os sistematizadores da filosofia, tinham suas escolas.

A filosofia grega nasceu em meio a uma crise caracterizada pela decadência da concepção mitíco-religiosa do mundo e do sistema político que essa visão sustentava. A filosofia foi a positivação de um saber propriamente humano, racional. Entre os gregos, entretanto, sobretudo como propunha Platão, nem todo 
indivíduo precisa filosofar, mas apenas aquele cuja natureza os fez governantes. Assim, poucos eram os que podiam aprender filosofia.

Esse saber propriamente humano, racional, foi tomado, já na Idade Média, como possibilidade de apropriação da tradição grega. Não para superá-la, mas para retê-la e usá-la na conversão dos bárbaros ao cristianismo. Segundo Pieper (1979), foi graças a isso que pudemos conhecer a filosofia dos gregos.

Com os conflitos religiosos e o Movimento Renascentista, o ensino passa a ter a finalidade de possibilitar ao indivíduo sua autonomia e poder de agir; a tradição deve ser apropriada apenas como instrumento para o fazer. É todo um movimento de negação da escolástica para afirmar essa nova concepção de educação. Mas continua-se a ensinar as filosofias de autores clássicos como forma de desenvolver a arte da retórica entre os nobres.

Ao mesmo tempo, temos a educação promovida pelos jesuítas, na contra reforma, que teriam elaborado regras para a escolha de opiniões de filósofos que pudessem ser utilizadas no ensino. Nessas regras, o princípio é o de não inovar:

Os mestres da filosofia não se apartem de Aristóteles em coisa alguma de importância, a não ser que se ofereça algum ponto contrário à doutrina que defendem geralmente as Universidades e muito mais se repugna a Fé ortodoxa (...) Não introduzam qualquer questão ou opinião nova que não esteja difundida por algum bom autor, sem consultar 0 assunto com os superiores, nem defendam algo contra os princípios dos filósofos e contra o uso corrente das escolas. Entendem também que, se houver alguns mestres inclinados a novidades ou de engenho demasiado livre, devem ser removidos do seu ofício de ensinar (DIAS, apud CARILHO, 1987, p. 191).

Já no contexto da educação do século XVIII, estruturada segundo a nova organização dos saberes cujas marcas principais são a nacionalização e a ampliação do ensino para outros segmentos sociais, através da escola, é que a filosofia ganhará um espaço mais amplo na educação, em substituição ao ensino da retórica. 
Os conteúdos inicialmente propostos para o ensino de filosofia, definidos por D'Alembert, segundo Carrilho:

(...) limitar-se-ia a Lógica a algumas poucas linhas; a Metafísica, a um resumo de Locke; a Moral puramente filosófica, às obras de Sêneca e Epicteto; a Moral cristã, ao sermão de Jesus Cristo na montanha; a Física, às experiências e à Geometria, que é, de todas as lógicas e físicas, a melhor (CARRILHO, 1987, P. 36).

Mas esses conteúdos não se limitavam apenas ao estudo histórico, de acordo com a finalidade pretendida que era a de despertar o "hábito de refletir $e$ raciocinar" (idem, p. 37) nos indivíduos.

Este programa, ainda segundo Carrilho, teria três objetivos principais que seriam os de "acolher, no ensino, as aquisições da filosofia moderna; ligar o ensino filosófico aos contributos da ciência moderna; proceder a uma clara separação de águas entre a filosofia e a religião” (idem, pp. 36-37).

Não é difícil notar, por aí, o quanto a filosofia ensinada na escola estava ligada ao emergente modo de viver e pensar o mundo. A filosofia separa-se do dogma religioso para juntar-se ao novo modelo empírico-matemático que sustenta a racionalidade científica e aos ideais de emancipação da humanidade pelo desenvolvimento dessa racionalidade.

Também a partir do século XVIII afirma-se o ecletismo. Encontramos, então, o que se chama estratégia eclética para o ensino de filosofia: defesa $e$ difusão de idéias que mesmo não sendo novas são valorizadas como tal, através do ensino. Como nos diz Derrida, o programa eclético de ensino de filosofia

compreende cadeias de tradição e de repetição cujos funcionamentos não são específicos a uma dada configuração histórica ou ideológica particular, e que se perpetuam desde os começos da sofística e da filosofia. Não só como uma espécie de estrutura fundamental e contínua que suportaria fenômenos ou episódios singulares. Com efeito, esta máquina profunda, este programa fundamental, 
é de cada vez revestido, reinformado, reempregue na sua totalidade por cada configuração determinada (DERRIDA apud CARILHO, 1987, p. 230).

O ecletismo estabeleceu-se na França, no século XIX, defindendo a filosofia acima de tudo como exame da natureza do espírito humano. Neste sentido, "o ensino de filosofia deve valorizar, introdutoriamente, a psicologia e a lógica, pois só elas podem conduzir ao conhecimento da verdade: a primeira pelo conhecimento que permite ter da atividade do sujeito, a segunda pela aprendizagem da arte de pensar" (idem, p.233).

Essa postura eclética é a que predomina até hoje no ensino de filosofia, na medida em que é com ele que ela é escolarizada. É uma tentativa de procurar condensar as filosofias num certo número de verdades indubitáveis, validadas de antemão por supor-se serem úteis à sociedade e suscetíveis de transmissão, ao mesmo tempo em que há uma recusa em ensinar sistemas, privilegiando, sem um critério explícito, teses compreendidas em vários sistemas.

Se atentarmos, agora, para a história da educação brasileira, veremos que a situação não guarda diferença. Desde a primeira escola fundada pelos jesuítas, em 1553, até os dias de hoje, somente em dois momentos a filosofia não esteve presente nos currículos das escolas brasileiras: nos primeiros anos da República e durante a Ditadura Militar.

Podemos notar, também, como bem diz Costa (1992), que o ensino de filosofia sempre teve caráter acessório e propedêutico; a filosofia sempre foi uma disciplina auxiliar incluída em políticas educacionais com finalidades extrafilosóficas: formação erudita, humanística, cientificista, tecnicista, entre outras.

Da experiência histórica com a educação filosófica, então, podemos aprender que a presença da filosofia na escola não significa, por si só, a condição de possibilidade de uma educação criadora de filosofias. A filosofia concebida como disciplina curricular da educação escolar, desde o século XVI tem se limitado ao estudo erudito, dogmático e cientificizado da história da filosofia. Os efeitos 
disso são basicamente de um aprender cuja função social e política é a conservação da tradição, sem possibilitar nova vida: conhecer o passado por ele mesmo.

\section{2 - A crítica de Nietzsche à tradição filosófica e à educação moderna}

Toda educação que deixa entrever no fim de sua carreira um cargo de funcionário ou um ganha-pão, não constitui uma educação para a cultura como nós a concebemos, mas uma indicação do caminho pelo qual se salva e se protege seu sujeito na luta pela existência (NIETZSCHE, 1973, p. 132).

O projeto geral de Nietzsche consiste em introduzir em filosofia o conceito de valor e de fazer filosofia como avaliação. Para ele, o problema filosófico por excelência é o problema dos valores: dos valores morais.

É dentro desse projeto que Nietzsche concebe um outro conceito de crítica: criticar é avaliar, mas avaliar é interpretar e apreciar, onde interpretar consiste em dar sentido próprio e apreciar consiste em avaliar a partir de valores dados, por um lado, mas, por outro, é também um momento de criação de valores, cujo critério último é a vida. Ou seja, da valorização resulta o valor propriamente dito.

As palavras de Deleuze dão sinais disso:

A filosofia crítica (de Nietzsche) tem dois movimentos inseparáveis: remeter todas as coisas, e toda origem de qualquer coisa, a valores; mas também remeter esses valores a qualquer coisa que seja como sua origem, e que decide sobre seu valor (DELEUZE, 1962, p. 2).

A avaliação nietzschiana é genealógica, consistindo na interpretação do valor da origem e do valor dos valores, para desmascarar os sujeitos e as razões das máscaras, bem como os fins pelos quais se conserva uma máscara quando se a remodela. É trabalho de desmistificação. 
No prefácio à Genealogia da Moral Nietzsche diz em que consiste propriamente avaliação genealógica:

Necessitamos uma crítica dos valores morais, e antes de tudo deve-se discutir o valor destes valores; e por isso é de toda a necessidade conhecer as condiçôes e os meios ambientes em que nasceram, em que se desenvolveram e se deformaram (...) conhecimento tal que nunca teve outro semelhante nem é possível que o tenha (NIETZSCHE, 1998, p. 11).

Com isso podemos dizer que a crítica, em Nietzsche, consiste em interpretar e avaliar os valores morais desde o contexto de suas origens, para saber de sua validade na perspectiva de vida ou do modo de viver de quem avalia. A crítica é perspectivista.

Neste sentido, a crítica nietzschiana é uma necessidade extemporânea de sempre avaliar os valores a partir da interpretação do contexto de sua criação e da valoração a paritr do presente, como condição da criação de novos valores.

O sentido da crítica é a criação e a sua função é a de possibilitar um futuro ativo, através da transmutação dos valores. Seu alvo são os próprios valores através dos quais pensamos na filosofia tradicional, que assumiram uma forma científica. Ele quer resgatar a filosofia como criadora, retirando-a do domínio da ciência que lhe empresta um valor meramente instrumental, formal e objetivo.

A crítica nietzschiana, em última análise, consiste na tentativa de desmascarar o universalismo dos valores estabelecidos segundo o critério da razão e em apontar para a vida em sua concretude primeira e individual.

Tentemos ir um pouco adiante em relação a essa concepção nietzschiana de filosofia.

A máscara que o filósofo carrega é a da vontade de verdade (busca do conhecimento) que, para Nietzsche, esconde uma vontade de poder e de dominação e, em última instância, não passa de moralização. Moralização 
entendida por ele como forma de dominação. A expressão científica da filosofia, radicalizada pela modernidade, busca no conceito a igualação do não-igual, isto é, serve para recordar uma vivência individual e única, um sentimento, mas que tem de convir a todos os casos semelhantes, porém, rigorosamente desiguais.

Assim, a verdade não passa de um valor moral. Valor estabelecido despoticamente pelos filósofos e que se tornou um hábito secular, uma obrigação para a vida coletiva, uma forma de dominar.

Não Ihes parece uma afronta à filosofia que se decrete, como hoje se faz com gosto: "A filosofia é crítica e ciência crítica - $e$ nada mais!" Essa valoração da filosofia pode gozar do aplauso de todos os positivistas da França e da Alemanha ($e$ é possível que agradasse até ao gosto e ao coração de Kant: recordem-se o título de suas obras principais -): nossos novos filósofos dirão, porém: os críticos são instrumentos dos filósofos, e por isso, por serem instrumentos, estão longe de serem filósofos! (NIETZSCHE, 1996, p. 117).

Nietzsche separa em duas categorias os filósofos: "os trabalhadores filosóficos" (os cientistas da filosofia ou da razão, os eruditos, os historiadores, os críticos) e os "filósofos propriamente ditos". Para ele, os últimos são criadores e legisladores:

(...) eles dizem "Assim deve ser!"; são eles que determinam o para onde? e o para que? do ser humano, e nisso têm a seu dispor o trabalho prévio de todos os trabalhadores filosóficos, de todos os dominadores do passado - estendem a mão criadora para o futuro, e tudo que é e foi torna-se para eles um meio, um instrumento, um martelo". Seu "conhecer" é criar, seu criar é legislar, sua vontade de verdade é - vontade de poder. (idem, p. 118)

O filosofar autêntico, para Nietzsche, consiste em criar novos valores e não apenas em reter valores já criados e tidos como verdadeiros. Os que se preocupam com a retenção, ele os chama de instrumentos; homens objetivos que se desresponsabilizam pelo espírito e estão subjugados por alguém mais poderoso. Os 
que criam, os verdadeiros filósofos só é possível o saber pela experiência ou ter o orgulho de não o saber: eles estão para além do bem e do mal.

Os efeitos disso é que o filósofo se opõe ao ideal democrático de submissão do indivíduo ao juízo da maioria. Querendo livrar os indivíduos da igualação conceitual e abstrata, da instrumentalização e objetividade científica, Nietzsche aponta para uma condição individual própria para o filosofar e para o dominar.

Adivinhei, com isso, em que medida uma espécie mais forte de homem teria necessariamente de pensar a elevação $e$ intensificação do homem em direção a um outro lado: seres superiores, para além de bem e mal, para além daqueles valores que não podem negar sua origem na esfera do sofrer, do rebanho e da maioria - procurei pelos esboços dessa inversa formação de ideal na história los conceitos "pagão", "clássico", "nobre", descobertos e dispostos de modo novo) (NIETZSCHE, 1983, p. 393).

Diferentemente da tradição moderna, então, Nietzsche não supõe que algum dia a humanidade possa chegar a uma perfeição racional. Ao contrário, ele entende ser a história da razão uma história de ilusão e que o seu devir se dá com o surgimento de grandes homens que possam liberar a humanidade da tradição que constitui a moralidade, o modo de viver do presente.

Neste sentido, a educação teria a tarefa de auxiliar a natureza no desenvolvimento de espíritos livres. A educação teria a finalidade de elevar os indivíduos à cultura, possibilitando o aparecimento desses modelos de homens: os gênios, os heróis.

Para tanto, seriam educadores aqueles que criassem as condições para que os educandos pudessem vir a serem eles mesmos seus próprios educadores $e$ desenvolvessem a potencialidade que lhes é dominante. Essa potencialidade dominante, entretanto, Nietzsche não a considera inata aos indivíduos, mas, sim, como produto de uma aprendizagem, de maneira que para que ela possa ser mantida e desenvolvida é preciso que todas as potencialidades presentes $e$ 
acumuladas pela humanidade sejam desenvolvidas no indivíduo para fortalecer aquela que o fará torna-se o que é.

Nietzsche com isso está a negar dois modos de educar. O primeiro ele o chama despótico, quando a educação visa a desenvolver apenas um dom no educando, formando especialistas; o outro ele o chama democrático, quando todos os dons são colocados ao mesmo nível e cujo produto é o homem burguês, o animal de rebanho, o igual.

Ele vê nesses dois modos de educar tendências que levam à decadência da cultura: o primeiro tende a reduzir a cultura, colocando-a a serviço de uma outra coisa, quer seja a ciência, quer seja o Estado; já o segundo tende a alargar ao máximo a divulgação da cultura, de modo que os valores dominantes contaminem a todos.

Essa segunda tendência põe em perigo a cultura própria de um povo na medida em que massifica a cultura dominante através de uma instrução elementar obrigatória a todos, somada ao que ele chama cultura jornalística ou pensamento do instante, da moda. A cultura de massa ocasionaria, na visão de Nietzsche, a perda do solo e das tradições de onde o gênio se nutre e amadurece, dificultando o desenvolvimento de espíritos livres, além de preparar homens apenas para viver o presente. Diz ele:

Logo, não é a cultura de massa que pode ser nossa finalidade, mas a cultura de indivíduos escolhidos, armados para executar grandes obras que permanecerão; sabemos bem que uma posteridade justa julgará a cultura de conjunto de um povo única e exclusivamente mediante os grandes heróis de uma época, aqueles que marcham sós, e que ela emitirá um juízo pela maneira como eles foram reconhecidos, favorecidos, honrados, ou rejeitados, maltratados, destruídos (idem, p. 119).

A primeira tendência, que reduz a cultura à especialização, por outro lado, marca a cultura técnico-científica, condenada a formar indivíduos que só vêem fragmentos e nunca a totalidade, limitando-se a deduzir sua coesão. Pois, uma 
educação voltada estritamente para a ciência é uma educação disciplinadora, em que o indivíduo se distancia cada vez mais da verdadeira cultura, vindo a ser fiel às pequenas coisas, às minúcias, a pontos específicos, esquecendo as questões de ordem geral da humanidade.

Essas duas tendências, segundo Nietzsche, convergem para um único ponto fundamental que ele encara como um problema de ordem moral e que diz respeito a uma sociedade regida pela economia. Aqui, o valor da educação e da cultura é meramente utilitarista, servindo de instrumento para o alcance do lucro, do máximo de ganho de dinheiro possível.

A moral que domina na economia exige a união entre inteligência $e$ propriedade, além de exigir uma cultura ligeira, fundamentada na informação, para que o indivíduo possa "rapidamente vir a ser um ser que ganhe dinheiro, mas também uma cultura bastante aprofundada para que se possa vir a ser um ser que ganhe muito dinheiro" (idem, p. 95), desprezando, portanto, o cultivo necessário aos grandes homens.

A fórmula de uma tal moral seria mais ou menos a seguinte, nas palavras de Nietzsche: "Quanto mais conhecimento e cultura possível - logo quanto mais produção e necessidade possível -, então tanto mais de felicidade possível" (idem, p. 94), pois a cultura, nessa perspectiva, só é visada e valorizada para o ganho, que equivaleria à felicidade na moralidade moderna.

Ao contrário disso, ele entende que a felicidade pretendida pela humanidade é o que a faz manter-se viva. Neste sentido, toda cultura e, por conseguinte, toda educação tem de ter em vista a vida.

E porque a vida precisa de uma cultura sadia torna-se imprescindível que as escolas e todas as instituições de ensino estejam voltadas para a cultura, pois só assim também será possível uma sociedade e uma humanidade sadias e vivas. Por isso Nietzsche chega a profetizar com entusiasmo: "um dia virá em que só se terá um único pensamento: a educação”. 
Agora, se considerarmos com Nietzsche que viver não é apenas lutar pela existência, mas, sim, ter uma vida ativa, criadora, e tendo em conta que educar é um permanente cultivo de si, uma permanente construção do indivíduo, uma educação que visa à vida teria o seguinte princípio: só aprender aquilo que se puder viver e abandonar tudo aquilo que instrui sem aumentar ou estimular a atividade $e$ a criação.

Esse princípio de Nietzsche, não é difícil notar, está ligado à sua idéia de que é preciso uma completa transmutação dos valores sob os quais vivemos. Vejamos o que ele diz:

Todas as açôes ligam-se a apreciaçóes de valor, e todas as apreciações de valor ou são pessoais ou são adquiridas estas últimas são, sem sombra de dúvida, as mais numerosas. As pessoas submetem-se mais às convençóes do que às suas próprias conviçôes (...) Desde a infância, convivem com as apreciaçóes de valor de seus avós. São guiadas por esses juízos adquiridos e raramente pensam na sua aprendizagem. Desde crianças, são albergues abertos a tudo e, como todo mundo, acreditam que a maior virtude é estar conforme às opinióes de todos (NIETZSCHE apud DIAS, 1991, pp. 66-67).

Essas condições gerais têm como efeitos, segundo Nietzsche, o que dissemos há pouco: uma educação que massifica a cultura, que está voltada estritamente para a ciência e que prepara os indivíduos para adquirir cultura com vistas a conquistar cargos e a ganhar dinheiro.

É o diagnóstico de Nietzsche, enunciado em "Sobre o futuro de nossos estabelecimentos de ensino", em que ele não deixa de reconhecer que esses são os princípios da educação moderna, de uma educação que domestica os indivíduos formando-os para a erudição ou para o exercício de funções e tornando-nos criaturas dóceis, indolentes e obedientes aos valores em curso. O que faz do indivíduo um ser sujeitado à moralidade. 
Por não estar de acordo com essa sujeição do indivíduo aos valores da moda, Nietzsche propõe que a educação não seja mera domesticação, mas um adestramento seletivo; a educação deve fazer com que os jovens possam aproveitar o trabalho das gerações que os antecederam, valendo-se de certas regras, porém, criando novas maneiras de apreciar. Um adestramento seletivo proporcionaria um agir voltado para o futuro, logo para a superação dos valores da moda, com vistas a um outro modo de viver.

\section{Condições de possibilidade do ensinar filosofia a partir de e contra Nietzsche}

A filosofia, tal como a entendemos juntamente com Nietzsche, não é um conhecimento progressivo nem conhecimento histórico e objetivo: ela é, sim, um modo de pensar que flui no ambiente de sua produção. Contudo, não entendemos, como Nietzsche, que filosofar seja privilégio de escolhidos, nem que a educação deva ser um adestramento seletivo. Filosofar e educar não são problemas de natureza, mas de possibilidade.

Por isso pensamos que é preciso exercitar o filosofar na escola, de modo que professores e alunos possam manifestar-se nesse exercício. Aqui nos entendemos com Nietzsche: sobre ser filósofo, só o podemos saber pela experiência.

O que estamos propondo, assim, é que o professor de filosofia não se limite a ser alguém que transmite conhecimentos, valores, hábitos, competências que não sejam os seus, mas que ele possa ser alguém que viva os conhecimentos, valores, hábitos e competências que pode criar, para que os alunos possam se situar em relação a isso.

Não se trata, tampouco, de fazer da vida do professor um modelo a ser seguido, mas, ao contrário, trata-se de o professor experimentar, agir, pôr em ação, pensar, juntamente com os alunos, aquilo que eles vivenciam: o filosofar. $\mathrm{O}$ professor de filosofia pode ser filósofo e permitir que os alunos possam também o 
ser, quando colocam o seu modo de pensar, de falar e de agir no mundo: condição para que possam ser interpretados e apreciados, avaliados e criticados.

Neste sentido, o que o professor precisa fazer, antes de preocupar-se com conteúdos, procedimentos e estratégias, é situar-se no pensamento, na ação e na fala, isto é, o professor precisa compreender-se como professor e como filósofo.

Carilho (1987), tratando a problemática da transmissibilidade filosófica indica duas formas pelas quais a filosofia é ensinada, hoje, e as denomina descritivo-doutrinária e conceptual-problemática.

A primeira diz respeito ao "ensino informativo em que se caracterizam autores, correntes", cujo efeito é a abstração da filosofia da experiência, neutralizando-a. Já o ensino de forma conceptual-problemática ele define como a forma autêntica de ensinar filosofia, uma vez que, aqui, a problematicidade e a explicação por conceitos, são os elementos fundamentais do ensino, da experiência do filosofar, portanto.

A idéia de Carilho é a de que é preciso partir dos problemas colocados pelas filosofias e seguir os passos percorridos pelo filósofo até as soluções, o que é o mesmo que ensinar a filosofar.

Se é válida a proposta de Carilho, então o conteúdo do exercício filosófico são as filosofias, porém, desde que ensinadas a partir da compreensão dos problemas que dão origem a elas. Acrescentamos, porém, deva poder contribuir para a compreensão dos nossos problemas atuais. Portanto, não há que se transmitir os produtos, mas encontrar no filosofar de outros um caminho possível para a avaliação e tomada de posição frente a problemas próprios do ambiente em que se filosofa.

O filosofar, assim, torna explícitos possíveis efeitos pedagógicos e políticos que lhes são intrínsecos, quais sejam, o de pensar conceitualmente, através da interlocução e da argumentação, com vistas ao encontro de sentidos e valores 
possíveis para o modo de viver e de organizar a vida dos indivíduos e da coletividade.

Não podemos, portanto, ensinar o filosofar sem ensinar filosofias; sem que alunos e professores tenham a possibilidade de acompanhar uma tal atividade a partir da produção filosófica do passado e da produção cultural que está relacionada ao modo de viver do presente (produção científica, artística, jornalística... e inclusive filosófica), pois a filosofia é ao mesmo tempo um modo de pensar - filosofar - e o produto obtido através deste modo de pensar - filosofias.

Sendo o filosofar, entretanto, um ato singular e pessoal do pensamento sobre algo que acontece, inclusive o próprio pensamento, é preciso que aluno e professor aprendam, juntos, a pôr esse pensamento no mundo sob uma linguagem em que ambos possam compreender-se e, assim, ter um múltiplo efeito crítico, aqui entendido como efeito político: o questionamento, a negação criadora do novo que põe a tradição em crise e exige uma tomada de posição que passa pela interpretação e pela avaliação. Escrevemos com Favaretto:

O pensamento crítico não provém, portanto, da simples discussão, ou da confrontação de posiçôes contrárias, ou da doação de soluçóes pelo professor. A crítica pode ser avaliada pela capacidade dos alunos em formular questóes $e$ objeçôes de maneira organizada, estruturada (rigorosa) (FAVARETTO, 1995, p. 81).

Neste sentido, como modo de educar pela auto-compreensão e pela compreensão do ambiente em que se vive, o filosofar certamente tem efeitos políticos, na medida em que cada indivíduo terá condições de intervir e modificar as relações com a tradição na qual estão inscritos, a partir de um pensar, de um falar e de um agir cotidianos, que ora passam a ser habitualmente críticos (tomadas de posição) e a serem experimentados, exercitados desde a sala de aula.

Não se trata, portanto, de pensar que a filosofia possa despertar em alunos e professores o interesse cego pela verdade, mas, antes, trata-se de possibilitar que nos situemos numa linguagem aberta que possibilite $\mathrm{o}$ afastamento, $\mathrm{O}$ 
estranhamento, a problematização da experiência, diferentemente da postura fechada que caracteriza o profissional especialista, o cientista da filosofia, o historiador, o erudito e o autor de livros didáticos.

Ensinar a filosofar na escola só será possível, portanto, na medida em que professores-filósofos e alunos-filósofos puderem ser concebidos no lugar e na condição de emissores de signos a serem interpretados e seguidos em momentos de interlocução.

Assim, o ensino de filosofia apresenta-se como construção conjunta de modos de pensar que se cruzam por intermédio da interlocução e da interação, agora situadas na escola, possibilitando a tomada de posição, a criação e o cultivo desses modos de pensar.

\section{REFERÊNCIAS BIBLIORGRÁFICAS}

ARANTES, Paulo E. et alii. A Filosofia e seu Ensino. Petrópolis: Vozes; São Paulo:

EDUC, 1995.

BORNHEIM, Gerd A. Introdução ao filosofar - o pensamento filosófico em bases existenciais. Porto Alegre: Globo, 1969.

CARRILHO, Manuel M. Razão e transmissão da Filosofia. Lisboa: Casa da Moeda, 1987.

CARTOlAnO, Maria T. P. Filosofia no ensino de $2^{\circ}$ grau. São Paulo: Cortez, 1985.

CHERVEL, André. História das disciplinas escolares: reflexões sobre um campo de pesquisa. Teoria \& Educação. Porto Alegre, n. 2, p. 177-229, 1990. 
COSTA, Marisa C.V. A Realidade do Ensino de Filosofia nas Escolas de $2^{\circ}$ Grau de Porto

Alegre. Porto Alegre: FACED/UFRGS, 1989.

. O ensino da Filosofia: revisando a história e as práticas curriculares.

Educação e

Realidade. Porto Alegre: UFRGS, v. 17, n. 1, p. 49-58, 1992.

DELEUZE, Gilles. Nietzsche et la Philosophie. Paris: Presses Universitaires de France,

1962

DELEUZE, G.; GUATTARI, F. Qu'est-ce que la Philosophie?Paris: Les Éditions de Minuit, 1991.

DIAS, Rosa M. Nietzsche Educador. São Paulo: Scipione, 1991.

FAVARETTO, Celso F. Notas sobre o ensino de filosofia. in: ARANTES, Paulo Eduardo.

A filosofia e o seu ensino. São Paulo: EDUC; Petrópolis: Vozes, 1995. pp. 77-85.

GIANNOTTI, José A. Por que filósofo? In: GIANNOTTI, José A. Filosofia miúda e

demais aventuras. São Pulo: Brasiliense, 1985. p. 11-16

GROUPE DE RECHERCHES SUR L'ENSEIGNEMENT PHILOSOPHIQUE. Qui a peur

de la philosophie? Paris: Flammarion, 1977.

LUZURIAGA, Lorenzo. História da educação e da pedagogia. 13 ed. São Paulo:

Nacional, 1981. 
MACHADO, Roberto. Nietzsche e a Verdade. Rio de Janeiro; São Paulo: Graal; Paz e

Terra, 1999.

MARTON, Scarlet. Nietzsche: a transvaloração dos valores. São Paulo: Moderna, 1993.

NIETZSCHE, F. Sur l'avenir de nos établissements d'enseignement. Écrits posthumes:

1870-1873. Oeuvres philosophiques complètes. Paris: Gallimard, 1973. v. 2

Obras incompletas. 2 ed. São Paulo: Abril Cultural, 1983.

. Crepúsculo dos Ídolos. Trad. Artur Morão. Lisboa: Edições 70, 1988.

Além do bem e do mal - prelúdio a uma filosofia do futuro. 2 ed. São Paulo:

Cia das Letras, 1992.

. O Livro do Filósofo. Trad. Ana Lobo. Porto: Rés, s.d.

A genealogia da moral. Uma Polêmica. São Paulo: Cia das Letras, 1998.

Humano, Demasiado Humano - um livro para espíritos livres. Paulo: Cia das

Letras, 2000.

PIEPER, Josef. Filosofia Medieval e Mundo Moderno. Madrid: Rialp, 1979. 